\title{
UK COMPETITION POLICY AND SHAREHOLDER VALUE: THE IMPACT OF MERGER INQUIRIES
}

\author{
by \\ Malcolm Arnold and David Parker \\ Cranfield Centre for Competition and Regulation Research \\ Cranfield University School of Management \\ Cranfield \\ MK43 OAL, UK \\ Tel: +44 (0)1234 754378 \\ Fax: +44 (0)1234 752136 \\ Email: david.parker@cranfield.ac.uk
}

Shareholder value v13.doc

Version: 24 March 2006

Word count, main text: 7577 


\title{
UK COMPETITION POLICY AND SHAREHOLDER VALUE: THE IMPACT OF MERGER INQUIRIES
}

\begin{abstract}
Some previous studies have suggested that competition regimes can destroy shareholder value. This study examines data on 50 mergers in the UK between 1989 and 2002. The study confirms the finding from earlier studies of greater gains to shareholders in target than bidding companies, but does not find evidence supporting overall loss of shareholder value to target company shareholders when a merger is prohibited. It finds evidence that when the regulatory regime is stable and well understood the capital market behaves efficiently in response to new information. However, for a sub group of the mergers involving companies with a new regulatory regime, of which industry and the market had little or no experience with respect to mergers, the capital market operated less efficiently.
\end{abstract}

Key words: mergers, competition policy, shareholder value, event study, privatised industries. 


\section{Introduction}

Previous studies have pointed to possible significant costs to the economy arising from state regulation (for a review see Blundell and Robinson, 2000). These costs take the form of the administrative costs of operating the regulatory system and the compliance costs to the company resulting from a competition inquiry in the form of legal and other advisory expenses and management time. However, these costs can be expected to be de minimis in relation to a company's value; typically such costs in the UK amount per merger to between $£ 500,000$ and $£ 2 \mathrm{~m}$. Hence, they are not the subject of this paper. A potentially much more important impact on shareholder value will result from the City revaluing the share price during an inquiry. Some previous studies have found that competition regimes can lead through share price movements to substantial losses to shareholders. This paper considers the impact of UK competition policy on shareholder value between 1989 and 2002. The purpose of the paper is not to measure the wider social welfare effects of competition policy, which would take into account the impact on consumers, suppliers, employees etc, but rather to concentrate on shareholder value, which is one part of social welfare. The effect of competition policy on shareholder value is an important subject for managers, who need to manage shareholder expectations during a competition inquiry, and investors.

The UK introduced its competition regime in 1948 with the establishment of the Monopolies Commission. In 1965 its remit was widened to inquire into mergers as well as monopoly markets (Wilks, 1999). Under the Competition Act of 1998, the Monopolies and Mergers Commission (MMC) became the Competition Commission (CC) and the powers of the Commission and the government department responsible for administering competition law, the Office of Fair Trading (OFT), were amended. Under the Enterprise Act 2002 the CC's decisions became determinative, that is to say they became final subject only to legal appeal. Previously the $\mathrm{CC}$ and before it the MMC had made recommendations to the Minister. In addition, the Act changed the test for mergers from "the public interest" (under Section 84 of the Fair Trading Act 1973) to "a substantial lessening of competition" test. In practice, however, since the 
1980s the Commission's reports have tended to concentrate upon a merger's competitive effects. ${ }^{1}$

The UK has a long-standing competition regime. In principle, over time the capital market should have built up experience of competition policy in the UK, allowing it to predict with some degree of confidence the likelihood of a referral to the MMC/CC and the MMC/CC's decision in the case of any referred merger. A reasonably stable and predictable competition regime should reduce distorting effects on share prices resulting from unexpected decisions by the competition authorities. Like a good tax system, a competition regime should achieve its goals, of preventing a lessening of competition, while minimising the costs, including costs imposed through share price movements in the stock market. Hence, in this paper we consider the impact on shareholder value of mergers referred to the MMC/CC between 1989 and 2002. This period was chosen because certain earlier studies, discussed below, had looked at competition policy and shareholder value up until the early 1990s and because the competition regime in the UK was changed substantially by the 2002 Enterprise Act, which took effect from June 2003.

During the study period of 1989-2002 the legal framework of competition regulation was based on the Fair Trading Act 1973 modified through the Competition Acts 1980 and 1998. However these did not change the concepts of qualifying mergers or the "public interest" test. The market share threshold for qualifying cases has remained constant at $25 \%$ since 1973 , and the asset size threshold was $£ 30 \mathrm{~m}$ from 1984, rising to $£ 70 \mathrm{~m}$ in 1994 . Hence there was a period of stability in the legislative framework governing competition regulation during the period 1989-2002. This regime had also existed for 15 years by the start of the study period, encompassing over 3200 qualifying cases of which 98 cases were referred for inquiry. As a result, the UK competition regime should have been a reasonably certain and well-understood regime during the study period.

\footnotetext{
${ }^{1}$ One of the authors is a Member of the Competition Commission. However, all comments made in this paper are made in a personal capacity. We would like to thank two referees and Sudi Sudarsanam , Paul Geroski and participants of a special session on mergers and acquisitions at the British Academy of Management Conference in September 2004, for their helpful comments on an earlier draft of this paper.
} 
The study period, however, contains a number of merger cases involving companies from industries in which new, sector-specific regulators were created, namely in water, electricity and telecommunications. The regulatory regimes for these industries were new, and the role of the CC/MMC had been modified to work with the industry specific regulators on competition issues relating to these industries. Therefore, merger cases involving companies from these industries may not have benefited to the same degree from regime stability and being well understood. One new aspect of their regulation was the roles played by the two regulators - the $\mathrm{CC} / \mathrm{MMC}$ and the sectorspecific regulators, such as OFTEL - and how far their responsibilities intertwined and overlapped. In the discussion below, for convenience, we refer to these industries as 'privatised industries', although in some cases, while subject to dual regulation, the firms concerned had not been privatised. Also, a number of the privatised industries had large numbers of small shareholders and it is possible that this may have impacted on the way the stock market responded to mergers.

The prime focus of the research is to understand any cost to shareholders arising from share price movements when companies desire to merge and the merger leads to a formal competition inquiry. It is therefore in the tradition of earlier studies, especially by Wier (1983), Franks and Harris (1993) and Forbes (1994). Consistent with the usage in competition policy, we use the term merger to include both friendly and hostile takeover bids.

In the case of any merger the view the capital market takes about the likelihood of a competition inquiry and the likely decision of the $\mathrm{MMC} / \mathrm{CC}$ will be reflected in the share price, in addition to any view taken about the intrinsic value of the merger itself. We study the mergers from the time they are publicly announced, encompassing the time from the announcement of the merger to a decision by the government to refer the merger to the $\mathrm{MMC} / \mathrm{CC}$ for inquiry. The period ends when a decision is made by the government following the $\mathrm{MMC} / \mathrm{CC}$ findings as to whether the merger should be prohibited or not, perhaps subject to behavioural or structural remedies, or when the merger is abandoned. ${ }^{2}$

\footnotetext{
${ }^{2}$ Before 2003 the MMC (later CC) reported to the Secretary of State for Trade and Industries, who had discretion not to accept the Commission's recommendation in the case of an adverse finding.
} 
While the capital market cannot be expected to predict the outcome of each stage of the inquiry process with perfect accuracy, the experience of investors should lead them to assess the likely outcomes for each merger. The capital market will form a collective view of the probability of referral to the Commission and concerning the Commission's final decision. Some evidence discussed below suggests that a competition regulator's decisions may be unexpected or differ from those anticipated by the capital market, but given rational expectations by investors, there should be no tendency towards systematic bias in the capital market's judgement. Competition regimes facing political interference might well be prone to an unexpected outcome, although in the UK the MMC/CC has operated with a high degree of independence (Wilks, 1999). Investors may also be expected to find it more difficult to forecast outcomes where mergers relate to industries where there is little or no track record of mergers or where there is a greater likelihood of non-competition issues influencing a regulator's decision. Good examples in the UK of the former are the privatised utilities, notably water and electricity, and of the latter the communications sector, where the government takes a particular interest in merger outcomes because of the possible effects on diversity in the media. In the 1990s these sectors were subject to a number of merger bids.

The paper contributes to an understanding of the costs of regulation and more especially competition policy. Whether competition policy increases social welfare depends on the improvements in economic efficiency it achieves, compared with its administrative and compliance costs including the impact on shareholder returns. The study's conclusions are also consistent with the importance for public policy of having a consistent and predictable competition policy. This is an important finding given that the number of countries with competition laws has increased from around 30 to over 90 in the last ten years (Singh, 2002). Where countries introduce new competition laws, they should expect that the impact of a competition inquiry on shareholder value may be greater than we find for the UK, because investors will lack experience of how the competition law is to be applied and therefore larger abnormal returns (both positive and negative) are to be expected. The next two sections of the paper review the existing literature in the field and detail the research method. The empirical results are then presented and discussed. The paper concludes by summarising the main findings and the contribution of the research to an 
understanding of the relationship between competition policy and shareholder value. Directions for future research are also highlighted.

\section{Literature review}

Most of the research into mergers has concentrated upon the effects on firm performance, measured mainly in terms of profitability, productivity and the impact on share prices. Profitability studies tend to show negative effects from mergers, while productivity and event studies tend to show more positive effects. For example, Meeks (1977) studied the effects of mergers in the UK on firm profitability. Meeks concluded that between a half and two-thirds of the firms in his UK sample suffered a fall in profits after a merger. Sirower (1997) studied stock market prices in US mergers. He found strong support for a negative relationship between the level of premium paid and the acquiring firms' performance. A flow of studies since has produced the following conclusions. While around a half or more of mergers fail to achieve the expected economic synergies, shareholders in target firms are likely to benefit more than shareholders in bidding firms (for a review of the earlier literature, see Chiplin and Wright, 1988, pp. 66-73, for later studies, see Sirower, 1997, Appendix A, pp. 145-166). This is because bidders may overestimate the economic gains from a merger and because of the level of premium they pay to shareholders in the target firm to win their acceptance of the takeover bid. Other studies have begun to look at mergers in terms of management and organisational changes, with a view to predicting the type of internal restructuring that should take place post merger if economic gains are to be maximised (for a review of this literature, see Schweiger and Goulet, 2000). By contrast, there seems to have been much less research into the interaction between competition policy and the economic consequences of mergers. Important exceptions are the studies by Eckbo (1983), Stillman (1983), Wier (1983), Franks and Harris (1993), Forbes (1994), Brady and Feinberg (2000), Aktas, de Bodt and Roll (2001), and Duso, Nevan and Roeller (2003), which we now review.

In 1983 Eckbo carried out event studies on a sample of 259 horizontal and vertical mergers in the USA, of which 79 were challenged by the government's anti-trust 
agencies. He found that there was no statistical evidence from rival company share price movements to support a collusive behaviour hypothesis for horizontal mergers. From this he concluded that horizontal mergers challenged by regulators had been based on cost saving efficiencies and not market power, and they were no more damaging to competition than vertical mergers. In the same year Stillman (1983) carried out a similar study of 11 horizontal mergers involving US companies between 1964 and 1972 which were challenged by the antitrust enforcement agencies. His results were consistent with those of Eckbo (1983). Both found a lack of statistical evidence to support referral to the anti-trust authorities on competition grounds. Research closer to our study is that by Wier (1983). Wier looked at the costs of defending mergers challenged by the US anti-trust enforcement agencies. Again using event studies, she considered the effects on market capitalisation measured by abnormal returns at key events in the regulatory process. Her finding was that, on average, merger complaint announcements occasion abnormal losses and large costs are born by shareholders of target firms if proposed mergers are cancelled. Wealth gains earned at the time of the bid announcement were cancelled out by losses by the time the competition inquiry ended. But she concluded that the effects on share prices will also be influenced by the ability of investors to accurately predict competition policy outcomes.

The relevant studies for the UK are those by Franks and Harris (1993) and Forbes (1994). Using event studies and data from a sample of 159 UK mergers referred to the MMC between 1965 and 1990, Franks and Harris (1993) examined evidence of shareholder value changes to bidder and target companies in mergers. They identified substantial losses to shareholders when the MMC rejected merger bids. In addition, they found that negative value returns occurred on referral and on the announcement of an adverse public interest finding by the MMC. Announcement of a favourable decision had a small positive effect. The value effects were greater and statistically significant for the target company, while the bidder company returns were smaller and statistically insignificant. They also found that a MMC rejection of a merger led to a substantial reduction in the gains to the target company's shareholders that had been recorded at the date of the merger bid. 
Forbes (1994) investigated the value impact of MMC references using event studies of 53 mergers in the period 1976 to 1990, although for bidding companies only. Abnormal returns were calculated for the initial announcement of the merger, announcement of referral to the MMC by the Minister, and the Commission's decision. The value effects were found to be broadly consistent with those in Franks and Harris (1993). Bidder returns were again small and not statistically significant.

More recently there has been an attempt to look at the impact on shareholder value of EU competition regulation. Brady and Feinberg (2000) examined 20 mergers from 1991 to 1995 subjected to EU competition investigation, after the introduction of the EU's merger regulations in 1990. This was the first time that the EU had taken formal powers to challenge mergers. They looked for evidence of regime effects (relating to cases grouped by EU member state and by industry sectors) and individual case effects of regulatory decisions on shareholder value. They found that the regime effects were weak. However, for individual cases enforcement of the merger regulations could have a substantial effect on individual company share prices. They also discovered that findings by the European Commission of "serious doubts" or the announcement of a "suspension" decision adversely affected the share price. In this case, the fact that investors seem to have had difficulty predicting inquiry outcomes, as reflected in share price movements, probably related to the fact that the merger regime in the EU was new. Another study, by Aktas, de Bodt and Roll (2001), looking at whether EU competition policy was biased against mergers involving nonEU firms, found clear confirmation that investors anticipate regulatory intervention. Hence, abnormal returns around the bid announcement date must be interpreted in the light of the probability and cost of regulatory intervention. Duso, Nevan and Roeller (2003) discovered a similar effect on competitors' share prices, drawing on the method proposed by Eckbo (1983) and Stillman (1983). They posited an anticompetitive merger would reduce competitive market forces within an industry and reduce downward pressure on prices and profit margins, which would be viewed positively by industry investors resulting in increased share prices for competitors. Hence a positive movement in competitors' share prices is interpreted as a view in the capital market that the merger is anti-competitive. From this they identified instances where the European Commission's findings on mergers may have been in error. 
The existing literature suggests, therefore, that alongside the costs to shareholders of firms defending anti-trust inquiries, in terms of professional fees and management resources, costs may be imposed on shareholders by the uncertainty of regulatory outcomes. In this paper we consider whether there is evidence since 1989 to support the findings of Wier (1983), Franks and Harris (1993) and Forbes (1994). All three observed a cost to shareholders of companies going through either the US and UK competition regulation processes. This cost arose from abnormal losses incurred on decision announcements, and in particular shareholders of target companies suffered a significant loss when an acquisition was prevented. We also consider whether there are any groupings of firms where stock market prices may have reacted in a different way to competition policy decisions than share prices in other mergers.

\section{Research Method}

In this paper event study techniques are used to examine 50 merger cases referred to the MMC/CC between 1989 and 2002. The mergers are listed in table 1 and were chosen from the Competition Commission's (incorporating the MMC's) list of merger cases on the basis of both bidder and target companies being listed on a public stock exchange for at least one year before the announcement of the $\mathrm{bid}^{3}$. Dates for events were found from company, Competition Commission and Stock Exchange press releases and from The Financial Times and Wall Street Journal. Event dates were confirmed from at least two sources if the original press releases were not available. Daily company share prices and market indices were obtained from DataStream. The final column of table 1 indicates those companies falling into the 'privatised industries' grouping (denoted by letter P). The remaining mergers fall into the 'other industries' category of the analysis. The table also shows the merger outcome, the regulatory decision by the competition authorities and whether the merger involved any competitive bidding; all of this data are used in the analysis below.

\footnotetext{
${ }^{3}$ Between 1989 and 2002 a total of 156 merger cases were referred to CC/MMC. Of these, in 50 cases both target and bidder companies were listed on stock exchanges, allowing analysis using event study methods in this research.
} 
(Table 1 here)

A market model was estimated using OLS regression comparing each company's daily share price changes (bidder and target) against changes in a major index for the stock exchange on which the companies were quoted (i.e. FTSE All Share index for UK listed companies). The model estimation period was from one calendar year before the bid announcement to two days before the final event. The final event was either the date of the completion of the merger deal in the Stock Market (either formal close of deal or the deal declared unconditional) or abandonment or prohibition of the bid. The estimation period was chosen so that the market model would reflect the variable and extended period between the initial bid and the final event, which can be up to a year in some cases. Event windows were excluded from the estimation of the market model. In this study the event windows were set at three days because this period should encompass immediate lead and lag effects ${ }^{4}$, while restricting the possibility of including share price changes resulting from events exogenous to the regulatory process. Setting a longer event window risks introducing effects on the share price that are independent of the announcement, including so-called "confounding" events in event studies.

For each bidder and target company the market model was estimated as follows:

$$
R_{i t}=\alpha_{i}+\beta_{i m} R_{m t}+\varepsilon_{i t}
$$

where $R_{i t}$ represents the return on security $i$ on day $t, \alpha_{i}$ is a constant, $R_{m t}$ represents the return on the market portfolio for day $t, \beta_{i m}$ is the regression coefficient of the relationship between security $i$ and the market index, and $\varepsilon_{i t}$ represents a random error term. Dummy values were used to remove event window days from the estimation regression. ${ }^{5}$ The abnormal return is the difference between the actual return and the expected return, and for any security, $i$, at time t, $A R_{i t}$, is:

$$
A R_{i t}=R_{i t}-\left(\alpha_{i}+\beta_{i m} R_{m t}\right)
$$

\footnotetext{
${ }^{4}$ To consider the effect of a regulatory or bid announcement on the share price on the day of the announcement only would exclude any effect on share prices resulting from lead effects (rumours, stock market anticipation of the announcement content) and lag effects (time for the market to assimilate the full likely effect on the share price of the announcement).

${ }^{5}$ Between the initial bid and the final event there are a number of event windows. These are excluded from the estimation data for the market model covering the period from one year before the initial bid to two days before the final event.
} 
The cumulative abnormal return (CAR) for event windows and the total bid was calculated by summing the daily abnormal returns:

$$
C A R_{i T}=\sum_{0}^{T} A R_{i t}
$$

where $C A R_{i T}$ is the cumulative abnormal return for security $i$ over event window $T$.

Average cumulative abnormal returns (ACAR) across $n$ firms is:

$$
A C A R=\frac{\sum_{i=1}^{n} C A R_{i t}}{n}
$$

All event windows were examined for confounding events occurring around the event period. In most cases event windows were clear of other potentially price sensitive announcements. In some cases, for example where a company was involved in multiple bids or other major company activities were ongoing, events sometimes overlapped. In such cases a judgement was made on the basis of whether the overlapping event was related to the merger being examined or not. If it was considered to be related, the event would be included in the abnormal return calculation, otherwise it was excluded.

The statistical significance testing for the ARs and CARs is discussed in depth in Salinger (1992), which shows the variance of the CAR is given by:

$$
\operatorname{Var}\left(C A R_{i t}\right)=\sigma^{2} T\left[1+\frac{T}{U}+\frac{T\left[\frac{r_{m 0}^{T}}{T}-\bar{r}_{m}\right]^{2}}{U \operatorname{Var}\left(r_{m}\right)}\right]
$$

where $T$ and $U$ are the lengths of the event window and estimation periods respectively, $\sigma^{2}$ is the variance of $\varepsilon_{i t}, \bar{r}_{m}$ and $\operatorname{Var}\left(r_{m}\right)$ are the mean and variance of the market return over the estimation period, and $r_{m 0}^{T}$ is the continuously compounded market return over the event window. 
The test statistic used is $t=C A R / \operatorname{Var}(C A R)$. When the degrees of freedom are large (e.g. greater than 200) this approximates to a normal distribution and $t_{v \rightarrow \infty}=Z$, where $v$ is the degrees of freedom.

When $\mathrm{n}$ firms are averaged the test statistic for the averaged group is calculated as:

$$
Z_{A C A R}=\frac{\sum_{i=1}^{n} Z_{i}}{\sqrt{n}},
$$

where $Z_{i}$ is the $\mathrm{Z}$ statistic for individual firms, and $\mathrm{n}$ is the number of firms in the group.

In some cases competitive bids for the same target were considered by the MMC/CC. These may have been on the basis of either one or both bidders being referred to the Commission. In all cases of multiple bidders, separate cases were analysed for each bidder.

Figure 1 summarises the process and the relevant decision points in UK competition policy and table 2 lists the possible outcomes from a referral. As a merger case progresses through the process, it is to be expected that the stock market takes a view on the probability of possible regulatory outcomes, drawing on investors' and their advisers' knowledge of competition law, past regulatory experience and case specifics (including expert opinion, media comment, rumours, etc). For example, the grounds on which a merger might be referred are covered by legislation and are well known and past decisions of the $\mathrm{MMC} / \mathrm{CC}$ are public knowledge. Table 3 summarises the merger activity between 1989 and 2002. Of a total of 9872 bids reported to the OFT, 3165 met the Fair Trading Act qualifying terms (either over $25 \%$ of market share for the combination or target assets greater than the prevailing limit of $£ 30 \mathrm{~m}$, later raised to $£ 70 \mathrm{~m}$ ). The OFT referred a total of 156 cases for investigation by the MMC/CC, of which 22 were subsequently prohibited outright after the Commission's inquiry.

(Figure 1 and Tables 2 and 3 here.) 
The starting point for the process is the announcement of the merger bid. In a simple case, the bidding company will usually offer to buy the target at a premium over the market price prevailing just before the bid announcement. The market will respond, re-valuing bidder and target companies based on the expected economic effects of the merger and the probable outcome of the bid. As part of the process, the City will take account of the possibility of referral to the $\mathrm{MMC} / \mathrm{CC}$ and will factor in an estimation of the probable outcome of an inquiry. After referral, as a case moves through the inquiry process the market will re-evaluate the merging companies at each step of the process as possible outcomes turn into certainties; for example, the probability of an adverse finding becomes 1 when the MMC/CC's decision is published (prior to that the probability lies in the range $>0$ to $<1$ ). If the merger is laid aside ${ }^{6}$ or abandoned by the companies involved part way through the process, the market will also re-value the companies based on this outcome. In the analysis below, the event study is based on daily percentage share price changes for the companies, allowing a direct comparison with the earlier work by Wier (1983), Franks and Harris (1993) and Forbes (1994), reviewed above.

If the regulatory regime is consistent and well understood by investors, efficient market behaviour can be expected to predominate. Investors will estimate the future value of the bidder and target companies, taking account of the nature of the proposed merger deal and the regulatory uncertainty that surrounds the merger. Efficient market behaviour in this discussion is intended to mean prices will respond quickly to new information and be linked to the fundamental value implicit in the announcement or regulatory "event". The fundamental value can be considered to be the NPV of the benefit (or detriment) arising from the event.

By contrast, the regulatory regime may not be so predictable if it is new or its legal framework undergoes significant changes, as in the study by Brady and Feinberg (2000) of European merger policy reviewed above. Newness and changes are accompanied by a lack of case history, making it more difficult for investors to predict accurately competition authority behaviour. In this situation, investors have more

\footnotetext{
6 "Laid aside" is the term used to describe MMC/CC inquiries that are stopped because the bidding party withdraws its bid after referral to the MMC/CC. The inquiries are technically "laid aside" and not abandoned because they are resurrected if the bid is later renewed.
} 
difficulty in assessing the possible regulatory outcome and the impact on the fundamental value of the events announced. In this climate of increased uncertainty, investors may turn to rumour, belief-based valuations or herd instinct, which may not be strongly linked to fundamental value.

There is ongoing debate about whether capital markets behave efficiently or not. A considerable amount of work has taken place to support the Efficient Market Hypothesis (EMH), as discussed in Fama (1969, 1970, 1991, and 1998). However, there has also been a strong challenge to the EMH view in the form of a development of an understanding of inefficient markets and behavioural finance. An overview of the subject area is given in Shiller $(1989,2001)$ and in Schleifer (2000). In this literature, the EMH does not appear to offer an adequate explanation of some commonly observed features of stock markets, particularly market volatility and the phenomenon of market bubbles, when prices become detached from the underlying fundamental values for a period before falling back. Our analysis simply requires that share prices reflect investors' current views of competition policy outcomes.

The study period in this paper - 1989 to 2002 - represents a period when the UK competition regime was relatively stable and well understood. Therefore, we would expect evidence in the mergers studied to support the proposition that the market behaved efficiently. However, there is a sub-set of the cases in the study that includes newly privatised industries, where the regulatory regime was new and involved sector-specific industry regulators as well as the MMC/CC. In these industries the OFT, the MMC/CC and the industry regulators could all play a part in deciding the outcome of any proposed merger. These 'privatisation' merger cases therefore entered relatively untested territory regarding the inter-working between industry regulators and the competition regulator in the study period. Another cause of additional uncertainty involved how structural changes in the privatised industries resulting from mergers might be viewed by government and to what degree government might intervene in competition decisions, for example by bringing pressure to bear on the sector regulators. For these reasons, the 'privatisation' sub-sample can be considered to be covered by a new regulatory regime with no or very little case history. Greater difficulty on the part of investors in understanding and valuing any merger events might therefore be expected and so we might expect to find some evidence of 
different market behaviour in this sub group. A further factor that might have impacted on the way the stock market responded to some mergers lies in the large numbers of small shareholders who purchased shares in privatised companies at the time of their privatisation. Such shareholders may lack the understanding of competition law and practice held by more seasoned investors and those with access to specialist advice.

To test for such effects, for part of the analysis the merger cases studied were split into two sub-groupings. The first contains the cases involving companies in what we term the 'privatised industries' and the second contains all the other merger cases studied, which is termed the 'other industries' panel. The propositions to be tested relate to how well market prices reflect the underlying value of the merger events on the companies, and are as follows.

Proposition 1. In merger cases where the deal is prohibited by the regulator or abandoned by the companies, the value change arising from bid specific events to the target company, from bid announcement to bid abandoned, is expected to be zero.

This proposition follows from the fact that, leaving aside the de minimis costs to companies (in relation to their values) of taking part in MMC/CC inquiries, because the merger is not completed the competition regime should have no effect on the fundamental value of companies, as reflected in their share prices. In effect, following the failed merger the fundamental value of the target company is restored to what it was immediately before the bid (ignoring, of course, other factors impacting on the share price since the bid was announced unrelated to the bid, such as tax changes or changes in the competitive environment). This is because any economic advantages resulting from the merger factored into the share price by investors in the target company at the time of the merger bid is removed once the bid is prevented or abandoned. $^{7}$

\footnotetext{
${ }^{7}$ A referee pointed out, correctly, that it is possible that because a merger bid puts a firm 'in play' by attracting attention to it as a potential takeover target the management may be 'shaken up' and the City may expect further bids. If such considerations affect the share price after a prohibition or abandonment of the original bid, then the proposition might not hold true. In this case, the abnormal return results will not be consistent with the proposition. In fact, our results are generally consistent with the proposition except for the 'privatised' industries, where other issues seem to impact on the way the share prices behave.
} 
Proposition 2. In merger cases where the deal is allowed (but not conditionally allowed) the value change arising from bid specific events to the target company from bid to deal close is greater than zero.

This proposition is valid because the share prices of target companies tend to rise in merger bids due to the bid premium required to induce investors to sell their shares in the target to the bidder. When the merger is permitted by the competition authorities, this gain is not offset by a counter move in the share price (as in the case of prohibited and abandoned bids).

Both propositions are applied to the target companies only for two reasons. Firstly the value of the bid to target company shareholders is driven by the bid premium and is usually positive in value. When the bid is withdrawn due to prohibition or abandonment, the value to target company shareholders disappears. This argument does not apply to the bidder company where the value to its shareholders is based on the difference between benefits from the bid and the cost of the bid including the premium paid, as viewed by the capital markets. This may be positive, negative or zero depending on the circumstances and the views taken (Sirower, 1997). Secondly target company returns are larger and statistically more significant than returns for bidder companies.

\section{The Empirical Results}

Firstly we establish the abnormal returns arising in each of the 50 merger cases studied between 1989 and 2002. These results are presented in Table 4. We then test for the two Propositions relating market behaviour. These results are presented in Tables 5 and 6.

In section A of table 4 the abnormal return results for all of the mergers studied are summarised, irrespective of the OFT decision on a referral and the outcome of a $\mathrm{MMC} / \mathrm{CC}$ inquiry. As can be seen, target company returns were greater than those for bidder companies and returns for the "other industries" group were greater than for the "privatised industries" group. Taking all the cases together, a small positive but 
statistically non-significant overall gain to shareholders of $1.0 \%$ for the bidder companies compares to a much larger and statistically significant gain of $14.3 \%$ for shareholders of the target companies. The finding that target company shareholders benefit most during mergers is consistent with much of the earlier merger literature (Sudarsanam, 2003, chapter 4).

(Table 4 here.)

Comparing industry groupings, section A of table 4 also shows that the overall results for bidder company cases in the 'privatised industries' grouping is a small loss ($2.9 \%$ ), which is statistically significant at the $1 \%$ level, compared to a small but not statistically significant gain of $2.2 \%$ in the 'other industries' grouping. By comparison target companies in both groups made significant positive returns of $8.3 \%$ and $16.2 \%$ for the 'privatised' and 'other' groups, respectively (both statistically significant at the $1 \%$ level).

In section B of table 4 cases are grouped by the regulatory decisions of the OFT ("waived through") and MMC/CC (the other cases considered by the OFT, i.e. which were referred to the MMC/CC, and were then later "allowed", "conditionally allowed" or "prohibited"). Also, the results when mergers were "laid aside" (abandoned) are included. Again target companies do better than bidders, irrespective of the inquiry decision. For bidders, taking all cases together, conditionally allowed cases showed the greatest return $(7.1 \%)$ while prohibited cases showed the lowest ($6.7 \%$ ), both being statistically significant. Overall bidder returns for other outcomes were small $(-1.8 \%$ to $1.4 \%)$ and not statistically significant. For target companies, returns were greater than for bidder companies and statistically significant for all decisions except laid aside cases. Highest returns for target companies were for allowed cases (20.7\%) and the least was for prohibited cases (4.8\%). Not surprisingly, prohibited outcomes gave the worst returns for both bidder and target companies, and the pattern was repeated when cases were divided into industry groups.

Particularly interesting are the abnormal returns where target companies are from what we refer to as 'privatised' (sector specific regulated) industries. Where a prohibition decision was announced following a MMC/CC inquiry, companies in 
these industries displayed the greatest negative abnormal returns of any decision announcement. Target companies in privatised industries returned a large statistically significant $12.6 \%$ loss, compared to a $0.4 \%$ (non-significant) gain in the case of prohibition announcements for target companies in the 'other industries' group (see table 4, section B, prohibited results, "Decision CAR"). The finding of a negative abnormal return for target companies on the announcement of a merger prohibition decision broadly agrees with the findings in the studies by Wier (1983), Franks and Harris (1993) and Forbes (1994).

However, a finding of negative returns on the announcement of a prohibition decision does not alone provide a sufficiently accurate picture of the overall effects of a competition inquiry. When we consider the overall return for target companies in cases with prohibited decisions, the return is $4.8 \%$ and this is made up of a statistically significant $5.4 \%$ return for the privatised industry group of firms and a 3.2\% nonsignificant return for the 'other industries' category (table 4, section B, prohibited results, "Overall CAR"). This finding is therefore greatly influenced by the privatised industry cases and is not consistent with the results in Wier (1983). She found an abnormal loss to shareholders of target companies due to prohibition resulting from competition inquiries and argued that the result is an additional cost of defending an anti-trust action in addition to normal legal and professional costs incurred. However our study agrees with Franks and Harris (1993), finding a gain to target company shareholders in prohibited cases over the whole bid and inquiry period. Our study suggests that there is no additional cost to target company shareholders when the regulatory process is taken as a whole, namely from announcement of a merger bid, through referral to the $\mathrm{MMC} / \mathrm{CC}$, to the inquiry decision prohibiting the merger. Especially when the privatised industry cases are excluded, the abnormal return is small and not statistically significant.

By contrast, bidder company shareholders experienced a significant loss in prohibited cases. Table 4 section B "prohibited" shows the overall bidder loss of $-6.7 \%$ was experienced equally in both the "privatised" and "other" industry groups (-6.5\% and $7.1 \%$ respectively), all abnormal returns are statistically significant at the 5\% level or better. Interestingly, this overall loss to bidder company shareholders in prohibited 
cases agrees with the figure of -6\% in Franks and Harris (1993), though their result was not statistically significant.

Other results in table 4 covering decisions to allow the mergers to proceed, that is to say the "allowed", "conditionally allowed" and "waived through" results, are also of interest. The abnormal returns to bidder and target companies show slightly different patterns. In the case of all mergers (privatised and 'other industries' together), for target companies the greatest returns were where there was an "allowed" decision (20.7\%). Bidder returns were highest for "conditionally allowed" cases (7.1\%), the two other decision groups show only small, statistically non significant returns. Again this is in broad agreement with Franks and Harris (1993) which showed cases allowed to proceed having returns for target and bidder companies of $38 \%$ and $6 \%$, respectively, over the whole bid and inquiry period.

While table 4 shows some differences between the returns for "privatised" and "other" industries, it is not possible to examine if market mispricing, due to a reduction of market efficiency, was a factor in those differences. Therefore, our study examines this directly by testing target companies returns against Propositions 1 and 2 described earlier. Table 5 shows the results of for the direct tests of Propositions 1 and 2.

In these tests any abnormal return results not significant at the 5\% level (two tailed) are interpreted as being equivalent to zero, in an attempt to ensure that any differences we find are statistically robust. The cases are again grouped into 'privatised' and 'other industries' categories. It can be seen that there is a much higher number of cases with a false result in the 'privatised' group. In order to test if the difference between the two industry groups is statistically significant, the results in table 5 are summarised in a contingency table, table 6. Applying Fisher's exact test to the contingency table indicates the difference between the two groups is statistically significant at the $10 \%$ level. From this finding we can conclude that the market behaviour in the 'others' grouping is more consistent with our Propositions, based on an efficient, well-informed capital market responding to merger inquiries, than is the case for the 'privatised' group of mergers. 
Merger cases involving 'privatised' industries occurred during the 1990s; in particular, there were three proposed mergers in both the water industry ${ }^{8}$ and in the electricity sector and two in communications. During this period investors' experience of how the competition authorities would respond to mergers in these sectors remained limited because there were few, if any, previous cases from which to draw lessons. It is to be expected, therefore, that investors would have had more difficulty in accurately assessing the likely impact of regulatory outcomes at each stage of the mergers involving water, electricity and communications companies. Moreover, the communications, water and electricity industries had their own, additional, sectorspecific regulators, which can be expected to have added to regulatory uncertainty at the time of mergers. The sector regulators police competition policy alongside the $\mathrm{MMC} / \mathrm{CC}$ and are important in recommending referrals of mergers to the MMC/CC. After referral they provide evidence to the Commission. The sector-specific regulators were mainly young in the $1990 \mathrm{~s}^{9}$ and at the time no one knew how far the regulators would allow the industrial structure established in water and electricity at privatisation to be changed. The government also took a special interest in mergers involving communications companies because of concerns about media ownership. Our findings are consistent with the view that less efficient market pricing of shares may have occurred in the case of mergers in these sectors as views in the stock market changed about the possible outcomes while the regulatory process relating to mergers was underway.

A further factor may have influenced market behaviour, which relates to the degree of non-institutional shareholding in privatised companies. At privatisation, the government had an objective of increasing the number of private shareholders in the UK and used the flotation of former state-owned industries to help achieve this aim. A large degree of equity held by individuals may have reduced the effectiveness of arbitrage traders in the capital market. At the same time, the behaviour of private shareholders may have been driven more by shareholder sentiment than by rational decisions based on fundamental value. With a combination of these factors we might expect a high degree of non-institutional shareholding to reduce market efficiency, in

\footnotetext{
${ }^{8}$ One of which was conditionally allowed and is therefore not included in table 5.

${ }^{9}$ The communications sector now has one regulator in the UK, Ofcom. In the 1980s and 1990s telecommunications had a new regulator, Oftel, while broadcasting and certain other fields of communications had their own dedicated regulators with longer histories.
} 
the sense of share prices being less linked to the underlying economic value brought about by the proposed mergers..

\section{Conclusions and Discussion}

Competition policy can be expected to impact on shareholder value during each stage of a merger inquiry process. Investors can be expected to reassess the probable final outcome of the inquiry at each step in the process, repeatedly revising the share prices of the merging companies. This paper has examined the impact of UK competition policy on shareholder value based on 50 mergers investigated by the $\mathrm{MMC} / \mathrm{CC}$ between 1989 and 2002. The study builds on earlier work on the effects of competition policy on shareholder value (especially Wier, 1983, Franks and Harris, 1993, Forbes, 1994) and examines whether the regulatory process decreases efficient market behaviour.

The empirical results support the findings of earlier work in the US and UK regarding the general level of shareholder value created for the bidder and target companies with target company shareholders being the main beneficiaries. They also support earlier findings that, on average, high abnormal losses are incurred by target company shareholders when a decision is announced by competition authorities prohibiting a merger. However, taking the regulatory process from initial bid to the MMC/CC's final decision, the study does not support the conclusion of Wier (1983) that target shareholders faced with a prohibition decision make an overall loss. Instead, a small gain to target company shareholder value is recorded.

UK competition policy has been in existence for over 50 years and while it has gone through a number of changes, most recently with the Competition Act 1998 and the Enterprise Act 2002, investors should have developed an understanding of the likelihood of a referral to the MMC/CC and the likely decision of the Commission. This understanding will be based on past experience involving similar mergers. It is likely that with the benefit of experience, investors' judgements of possible competition policy outcomes will be reasonably stable. This offers one possible explanation for the small percentage losses to target company shareholders reported 
by Wier (1983) compared to the results from this study, which found a small gain to shareholders in target companies. Wier's study deals with a different competition regime, that of the US, and perhaps the US stock market had more difficulty in the period studied in correctly anticipating competition policy decisions.

The results also indicated that mergers involving industries in the water, electricity and communications industries that were subject to competition inquiries showed less efficient market behaviour than those in other industries. The explanation for this possibly lies in the greater uncertainty that surrounded the response of regulators to mergers in these sectors. The water and electricity sectors had been given a particular organisational structure at privatisation and it was unclear whether the regulators would allow this structure to be altered through mergers. The government was known to take a special interest in the future of communications because of the perceived importance of this industry for national wellbeing. The 'privatisation' cases may have experienced share price changes that were influenced by inexperience on the part of investors of the dual regulatory regime that exists for these sectors in the UK, involving both the $\mathrm{MMC} / \mathrm{CC}$ and sector-specific regulatory offices. Another possible explanation relates to the large number of smaller shareholders in privatised firms as a result of government policy at privatisation. Our research was unable to separate out these different possible explanations because of the method used.

In summary, the study identifies that where a competition policy regime is stable and understood, there is no evidence of adverse overall costs due to share price movements for shareholders of target companies, when a merger bid is taken in its entirety from announcement to completion. Cases were also tested for evidence of efficient market behaviour using Propositions 1 and 2. Both Propositions are based on the assumption of efficient market behaviour and provide a yardstick against which cases are tested directly. Proposition 1 applies to merger cases where the deal is prohibited by the regulator or abandoned by the companies, and the overall value change arising from bid events to the target company, is expected to be zero. Proposition 2 applies to merger cases where the deal is allowed (but not conditionally allowed), the overall value change arising from bid events to the target company being greater than zero. While the "other" industry group cases matched both propositions, the "privatised" industry group failed to match in about half on the 
cases. This provides evidence that the market behaviour differed between the two groups. The "other" industry group, operating in the more stable and mature regulatory regime, showed evidence of efficient market behaviour having taken place. However the "privatised" industry group with the dual regulatory structure, of which investors had less experience, showed evidence of less efficient market behaviour. The evidence is consistent with a stable regulatory regime supporting efficient market behaviour. The less efficient market behaviour in the "privatised" group could have resulted from two possible causes. Firstly, investor uncertainty in predicting decisions of the newer regulatory structure and secondly, the high level of non-institutional shareholding in privatised companies may have reduced market efficiency. This finding suggests that where major changes to merger policy are introduced, it is to be expected that a period of adjustment will follow for investors, during which experience is being gained, before more efficient market behaviour returns, and investors, managers and policy makers should be cognisant of this when making plans. 
Table 1: The Merger Cases Included in the Study

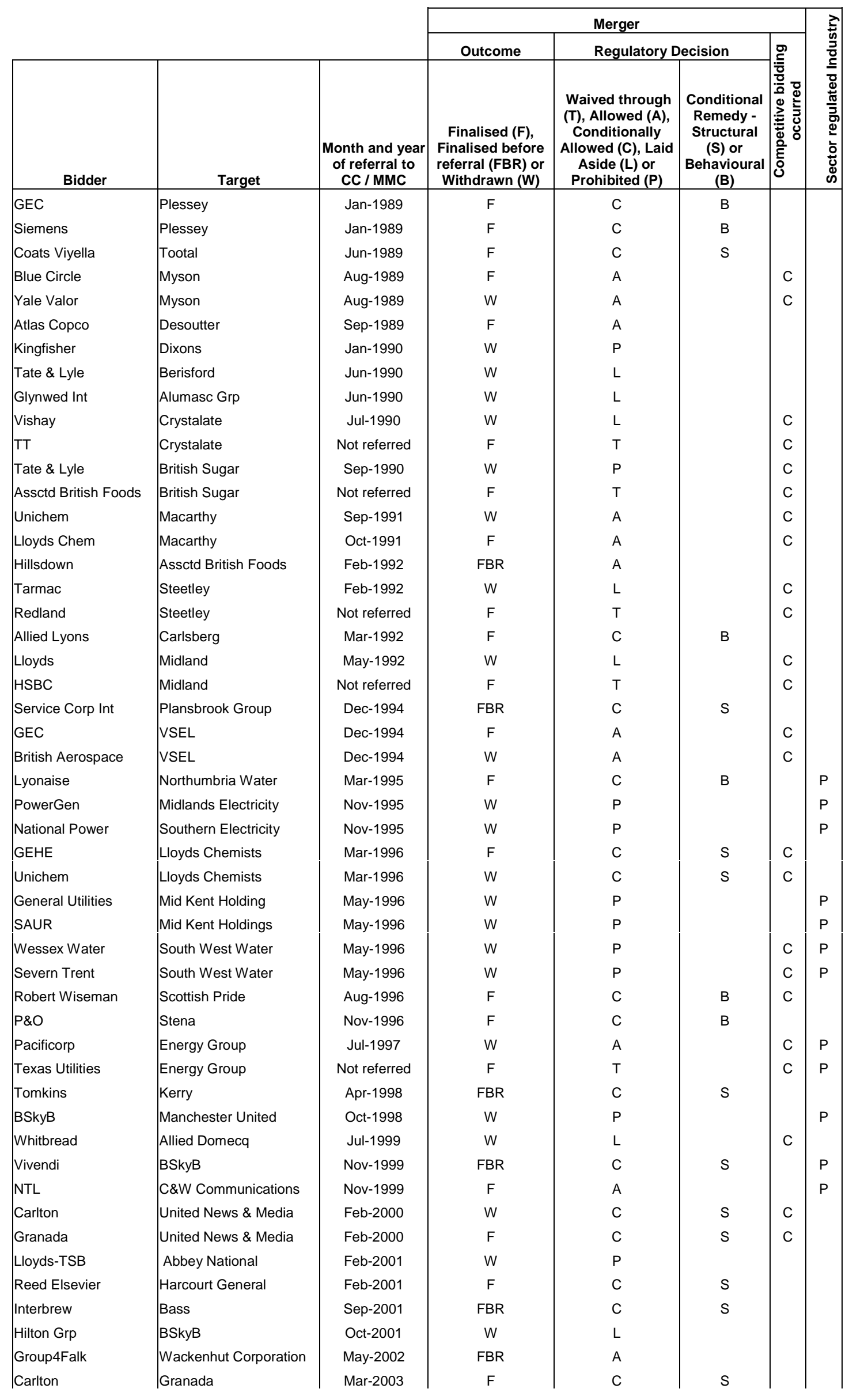


Table 2: Possible Outcomes following Referral of a Bid to the MMC/CC

\begin{tabular}{|c|c|}
\hline Decision of the $\mathrm{MMC} / \mathrm{CC}$ and the type of remedy prescribed & $\begin{array}{c}\text { Designation } \\
\text { of the } \\
\text { outcome }\end{array}$ \\
\hline The bid is found to have no adverse affects & Allowed \\
\hline \multicolumn{2}{|l|}{$\begin{array}{l}\text { The bid is found to have adverse affects and a remedy is prescribed. The } \\
\text { remedy is: }\end{array}$} \\
\hline Behavioural (e.g. price control or other operational undertakings) & $\begin{array}{l}\text { Behavioural } \\
\text { remedy }\end{array}$ \\
\hline Structural (e.g. divestment of some assets) & $\begin{array}{l}\text { Structural } \\
\text { remedy }\end{array}$ \\
\hline $\begin{array}{l}\text { Prohibition of the merger including de-merging if the merger has been } \\
\text { completed. }\end{array}$ & $\begin{array}{l}\text { Merger } \\
\text { prohibited }\end{array}$ \\
\hline The bid is abandoned by the bidding company. & $\begin{array}{l}\text { Merger laid } \\
\text { aside }\end{array}$ \\
\hline
\end{tabular}


Table 3: Summary of acquisitions and mergers activity $1989-2002$ and competition inquiry decisions.

\begin{tabular}{|r|c|c|}
\hline \multicolumn{1}{|c|}{$1989-\mathbf{2 0 0 2}$} & Number & $\begin{array}{c}\text { \% of all } \\
\text { mergers }\end{array}$ \\
\hline All acquisitions and mergers: & & \\
\hline All mergers $^{\mathbf{1}}$ & 9872 & 100 \\
\hline Qualifying cases & 3165 & 32.1 \\
\hline Referrals made to CC/ MMC & 156 & 1.6 \\
\hline Decisions made by CC / MMC on referrals: & & \\
\hline Adverse finding $^{\mathbf{3}}$ & 71 & 0.7 \\
\hline No adverse findings & 61 & 0.6 \\
\hline Laid aside & \\
\hline All decisions made by CC / MMC & 25 & 0.3 \\
\hline Remedies in adverse findings cases & 157 & 1.6 \\
\hline Behavioural $^{\mathbf{3}}$ & 20 & 0.2 \\
\hline Structural $^{\mathbf{3}}$ & 29 & 0.3 \\
\hline Prohibited $^{\mathbf{3}}$ & 22 & 0.2 \\
\hline
\end{tabular}

\section{Sources:}

1. Office of Fair Trading: Annual Report: Number of acquisitions of UK companies published in Acquisitions and Mergers in the UK (pre 1994 but excludes the financial sector) or First Release (1994 and later) by the Office of National Statistics.

2. Office of Fair Trading: Annual Report.

3. Competition Commission: Website http://www.competition-commission.org.uk/: Inquiries 
Table 4: Summary of the Abnormal Returns

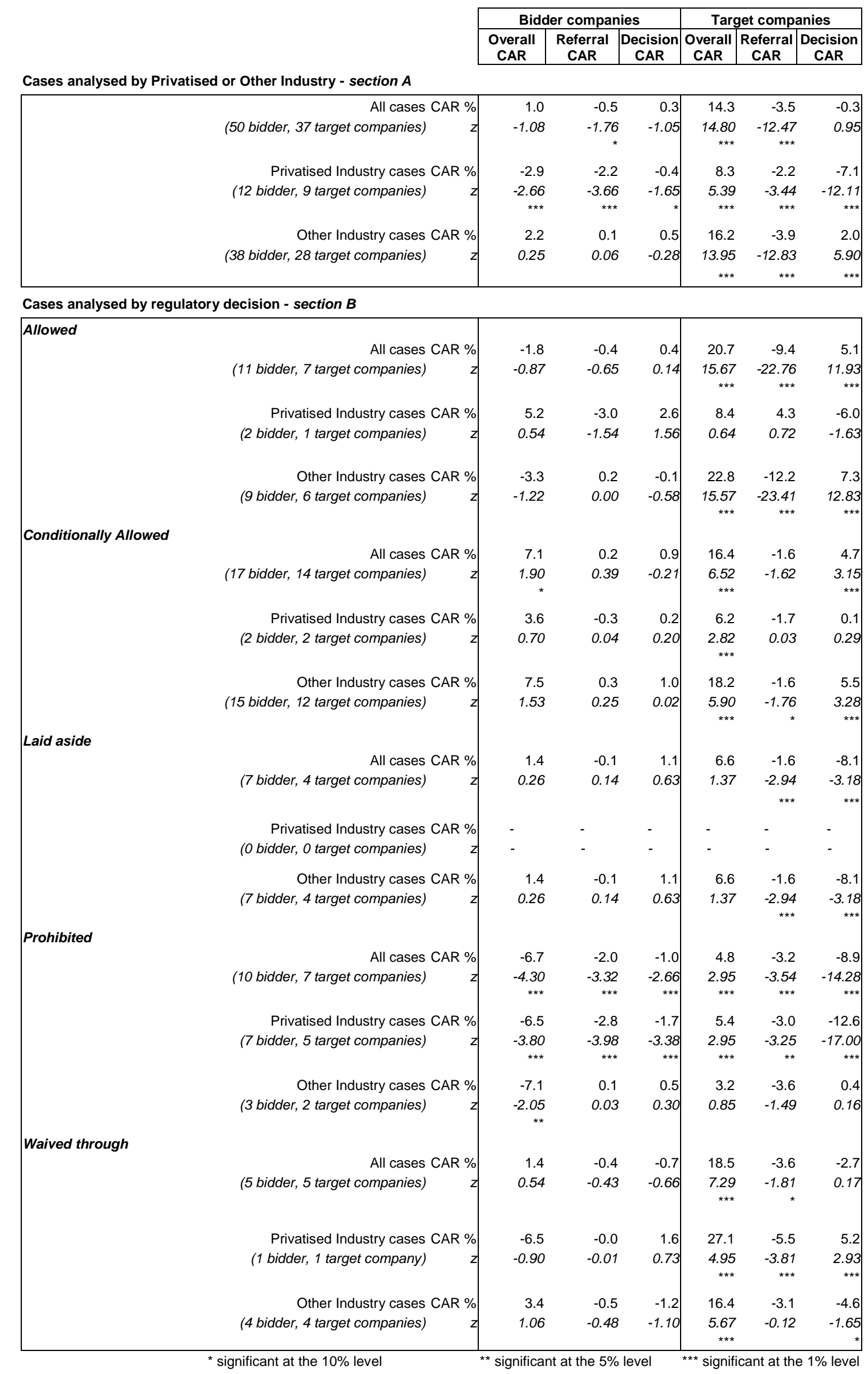


Table 5. Results of tests for propositions 1 and 2.

\begin{tabular}{|c|c|c|c|c|}
\hline Case (bidder - target) & $\begin{array}{l}\text { Total target } \\
\text { abnormal } \\
\text { returns \%* }\end{array}$ & $\boldsymbol{Z}$ & $\begin{array}{l}\text { Proposition1 } \\
\text { For } \\
\text { Prohibited } \\
\text { and Laid } \\
\text { Aside cases } \\
\text { target, AR=0 } \\
\text { (Z }>1.96)\end{array}$ & $\begin{array}{l}\text { Proposition } 2 \\
\text { For Allowed } \\
\text { and Waived } \\
\text { Thro' cases } \\
\text { target, AR>0 } \\
(Z>1.96)\end{array}$ \\
\hline
\end{tabular}

\section{Privatised Industries}

\section{Allowed}

NTL - C\&W Communications

$10.2 \%$

0.68

False

\section{Prohibited}

BSkyB - Manchester United

$\begin{array}{rrr}21.4 \% & 3.94 & \text { False } \\ 3.6 \% & 1.01 & \text { True } \\ 8.8 \% & 2.30 & \text { False } \\ -0.8 \% & -0.10 & \text { True } \\ 2.1 \% & 0.36 & \text { True }\end{array}$

Waived through

Texas Utilities - Energy Group

$28.3 \%$

True

\section{Other Industries}

\section{Allowed}

GEC - VSEL

Lloyds Chem - Macarthy

Atlas Copco - Desoutter

Blue Circle - Myson

$\begin{array}{rrr}31.7 \% & 3.96 & \text { True } \\ 31.1 \% & 4.50 & \text { True } \\ 82.1 \% & 22.93 & \text { True } \\ 38.3 \% & 7.21 & \text { True }\end{array}$

\section{Laid aside}

Tate \& Lyle - Berisford

$\begin{array}{rrr}7.7 \% & 0.83 & \text { True } \\ 2.9 \% & 0.50 & \text { True } \\ 17.5 \% & 1.71 & \text { True } \\ 14.9 \% & 1.31 & \text { True }\end{array}$

Glynwed Int - Alumasc Grp

Hilton Grp - BSkyB

$14.9 \%$

1.31 True

\section{Prohibited}

Lloyds-TSB - Abbey National

$\begin{array}{rrr}-6.8 \% & -0.71 & \text { True } \\ 16.6 \% & 2.01 & \text { False }\end{array}$

Kingfisher - Dixons

\section{Waived through}

Redland - Steetley

$\begin{array}{lll}70.4 \% & 4.57 & \text { True } \\ 73.6 \% & 6.11 & \text { True } \\ 37.9 \% & 2.04 & \text { True }\end{array}$

HSBC - Midland

$37.9 \%$

2.04

True

* Percentage ARs are based on total currency abnormal returns for bid specific events as a percentage of the share price two days before bid announcement. 
Table 6: Summary of the Results in Table 5 for Propositions 1 \& 2

\begin{tabular}{|l|c|c|c|}
\hline True or False results & $\begin{array}{c}\text { Privatised } \\
\text { Industries }\end{array}$ & $\begin{array}{c}\text { Other } \\
\text { Industries }\end{array}$ & Total \\
\hline TRUE & 4 & 12 & 16 \\
\hline FALSE & 3 & 1 & 4 \\
\hline Total & 13 & 7 & 20 \\
\hline
\end{tabular}

$(p$ - value $=0.101($ two sided $)$

The difference between the 'Other Industries' and the 'Privatised Industries' groups is significant at the 10\% level using Fisher's Exact Test. 
Figure 1

Flow Chart of the UK Merger Referral and Inquiry Process showing Main Decision Events.

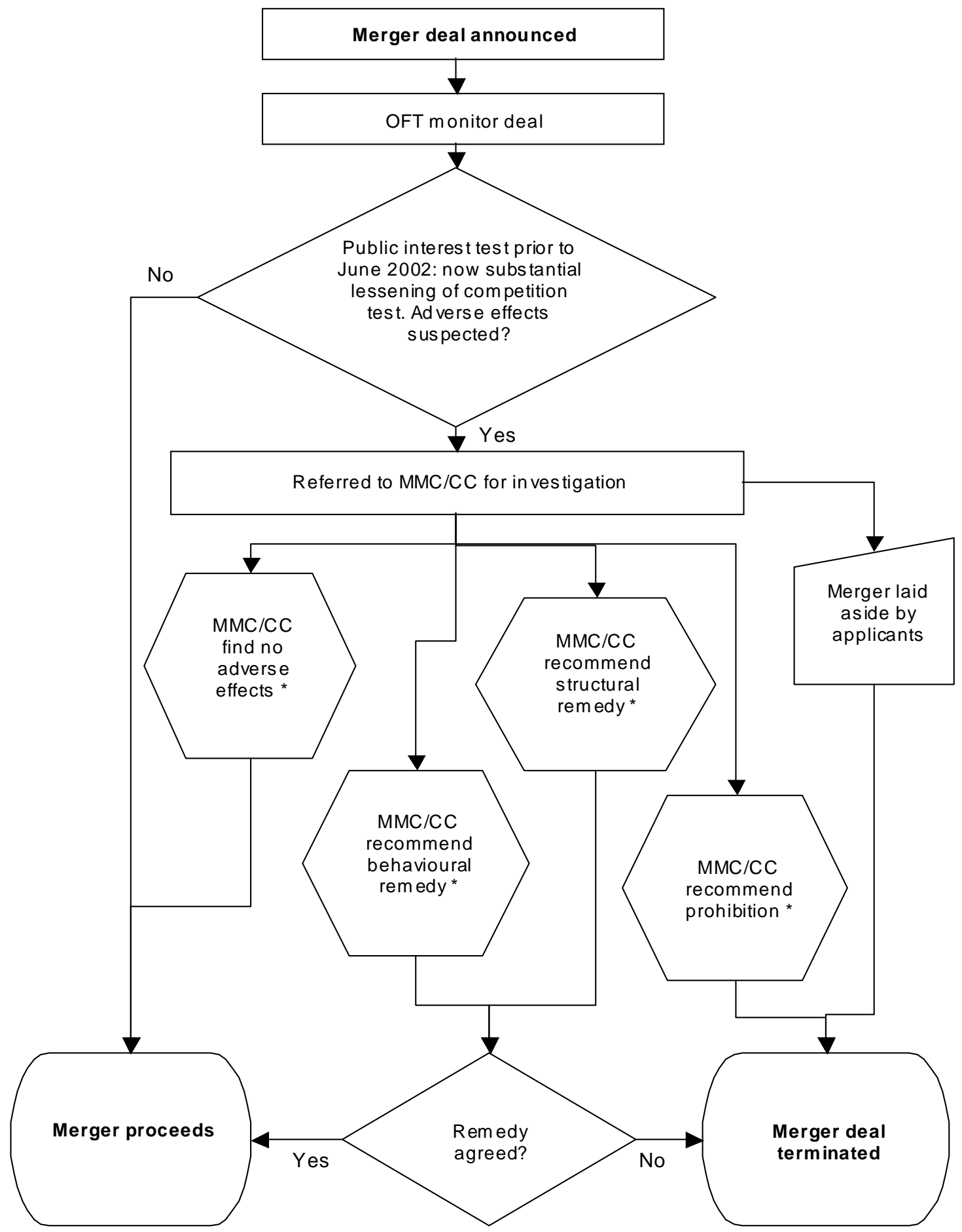

* Before 2002 if the Minister disagreed with an adverse decision by MMC/CC, he/she could reject the findings or apply a different remedy. Since June 2002 the CC decision and decision on rem edies is normally final. 


\section{References}

Aktas, N., de Bodt, E. and Roll, R. (2001), Market Response to European Regulation, University of California, eScholarship Repository: paper no 12-01.

Blundell, J. and Robinson, C. (2000). Regulation Without the State... the Debate Continues, Institute of Economic Affairs, London.

Brady, U. and Feinberg, R. (2000) An examination of stock-price effects of EU merger control policy, International Journal of Industrial Organization, 18, 885-900.

Chiplin, B. and Wright, M. (1988). The Logic of Mergers: The competitive market in corporate control in theory and practice, Institute of Economic Affairs, London.

Duso, T., Nevan, D. and Roeller, L. (2003), The Political Economy of European Merger Control: Evidence from Stock Market Data, WZB - Berlin.

Eckbo, B. (1983) Horizontal mergers, collusion, and stockholder wealth, Journal of Financial Economics, 11, 241-273.

Fama, E. (1970) Efficient Capital Markets: A review of theory and empirical work., Journal of Finance, 25, 383-417.

Fama, E. (1991) Efficient Capital Markets. 2., Journal of Finance, 46, 1575-1617.

Fama, E. (1998) Market efficiency, long-term returns and behavioural finance, Journal of Financial Economics, 49, 283-306.

Fama, E., Fisher, L., Jensen, M. and Roll, R. (1969) The adjustment of stock prices to new information., International Economic Review, 10, 1-21.

Forbes, W. (1994) The shareholder wealth effects of MMC decisions., Journal of Business Finance and Accounting., 21, 763-790.

Franks, J. and Harris, R. (1993) In European Mergers and Merger Policy(Eds, Bishop, M. and Kay, J.) Oxford University Press, Oxford.

Meeks, G. (1977). Disappointing Marriage: A Study of the Gains from Merger, Cambridge University Press, Cambridge.

Salinger, M. (1992) Standard Errors in Event Studies, Journal of Financial and Quantitative Analysis, 27, 39-53.

Schleifer, A. (2000). Inefficient Markets: An introduction to Behavioural Finance, Oxford University Press Inc., New York.

Schweiger, D. and Goulet, P. (2000) In Advances in Mergers and Acquisitions, Vol. 1 (Eds, Cooper, C. and Gregory, A.) Elsevier Science Inc., New York, pp. 6191.

Shiller, R. (1989). Market volatility, MIT Press.

Shiller, R. (2001). Irrational Exuberance, Princeton University Press.

Singh, A. (2002) Competition and Competition Policy in Emerging Markets: International and Developmental Dimensions., ESRC Centre for Business Research, University of Cambridge, Working Paper Series., Working Paper No.246, Also published in the G-24 Discussion Paper Series, no. 18, UNCTAD and Center for International Development Harvard University.

Sirower, M. L. (1997). The Synergy Trap, The Free Press, New York. 
Stillman, R. (1983) Examining Antitrust policy towards Horizontal Mergers, Journal of Financial Economics, 11, 225-240.

Wier, P. (1983) The Cost of Anti Merger Lawsuits, Journal of Financial Economics, 11, 207-224.

Wilks, S. (1999). In the Public Interest: Competition policy and the Monopolies and Mergers Commission, Manchester University Press., Manchester. 